\title{
Antifungal Activity of Securinine against Some Plant Pathogenic Fungi
}

\author{
Ashok K. Singh ${ }^{1 *}$, M. B. Pandey ${ }^{1}$, Sarita Singh ${ }^{1}$, Anil K. Singh ${ }^{2}$ and U. P. Singh \\ ${ }^{\prime}$ Department of Medicinal Chemistry, Institute of Medical Sciences, Banaras Hindu University, Varanasi - 221005, India \\ ${ }^{2}$ Department of Dravya Guna, Institute of Medical Sciences, Banaras Hindu University, Varanasi - 221005, India \\ ${ }^{3}$ Department of Mycology and Plant Pathology, Institute of Agricultural Sciences, Banaras Hindu University, Varanasi - 221005, India
}

(Received February 11, 2008. Accepted April 3, 2008)

The alkaloid securinine was assessed against spore germination of some plant pathogenic and saprophytic fungi (Alternaria alternata, Alternaria brassicae, Alternaria brassicicola, Curvularia lunata, Curvularia maculans, Curvularia pallenscens, Colletotrichum musae, Colletotrichum sp., Erysiphe pisi, Helminthosporium echinoclova, Helminthosporium spiciferum, Heterosporium sp.). Spore germinations of all the tested fungi were inhibited. Alternaria brassicicola, $C$. Iunata, $C$. pallenscens and $H$. spiciferum were highly sensitive as complete inhibition of spore germination was observed at very low concentrations (200 ppm).

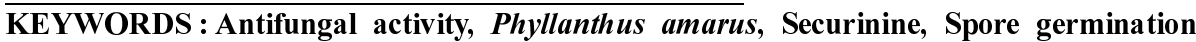

The crude plant extracts and a number of individual isolated principles from plants have been used in vitro, in greenhouse and also in open field conditions against several plant pathogenic fungi (Kobayashi et al., 1987; Maillard et al., 1987; Singh et al., 1995; Prithiviraj et al., 1996, 1998; Sarma et al., 1999). The compound ajoene isolated from Allium sativam (garlic) and neemazal, a product of Azadirachta indica (neem) have been used successively against powdery mildew (Erysiphe pisi) of pea under field conditions (Singh et al., 1995; Prithiviraj et al., 1998). Many alkaloids isolated from plants are known to exhibit antifungal activity at very low concentrations (Singh et al., 2000; Maurya et al., 2002). However, the effect of the alkaloid securinine, isolated from Phyllanthus amarus on spore germination has not been reported so far. We report here the antifungal activity of this compound for the first time.

The plant $P$. amarus (Family: Euphorbiaceae) is distributed in tropical and sub-tropical regions of the world. The herb is bitter in taste and is reported to possess astringent, deobstruent, stomachic, diuretic, febrifugal and antiseptic properties. It has been reported that $P$. amarus is reasonably safe and effective in acute viral hepatitis specially hepatitis B (Thyagrajan et al., 1988). A number of flavonoids, lignans, triterpenoids, organic acids and alkaloids have earlier been reported in literature (Joshi et al., 1986; Singh et al., 1991; Huang et al., 1992). The antifungal activity of ent-norsecurinine isolated from $P$. amarus has also been reported (Goel et al., 2002).

\section{Materials and Methods}

The whole plant of P. amarus was collected from Vara-

nasi and dried in sun light. The dried, powdered whole plant $(4 \mathrm{~kg})$ was extracted with methanol in a Soxhlet extractor. The methanol extract was dried on water bath and extracted with $7 \%$ aqueous citric acid. The acidic fraction was basified with $\mathrm{NH}_{4} \mathrm{OH}$ and extracted with $\mathrm{CHCl}_{3}$. The $\mathrm{CHCl}_{3}$ fraction was concentrated and chromatographed over $\mathrm{SiO}_{2}$ gel column eluting with solvents of increasing polarity and each eluted fraction was monitored by thin layer chromatography for their homogeinity. Fractions eluted from $\mathrm{CHCl}_{3}$-methanol $(1: 2)$ were mixed together and crystallised from methanol which furnished an alkaloid $(56 \mathrm{mg})$, as colourless granules, Rf 0.45 $\left(\mathrm{CHCl}_{3}\right.$-methanol, $\left.4: 1\right)$, m.p. $140 \sim 43^{\circ} \mathrm{C}$. It exhibited IR absorption bands at 1840 and $1760 \mathrm{~cm}^{-1}$ and UV absorption maxima at $256 \mathrm{~nm}$. Its molecular formula was determined as $\mathrm{C}_{13} \mathrm{H}_{15} \mathrm{NO}_{2}$ from its molecular ion peak at $\mathrm{m} / \mathrm{z}$ $217[M]$ in the mass spectrum. The spectral data, i.e. ${ }^{1} \mathrm{H}-$ $\mathrm{NMR},{ }^{13} \mathrm{C}-\mathrm{NMR}$ and MS were identical with reported data of securinine. Finally, it was identified as securinine

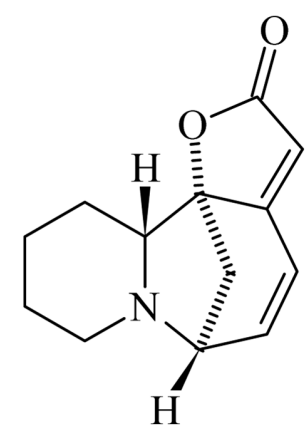

1

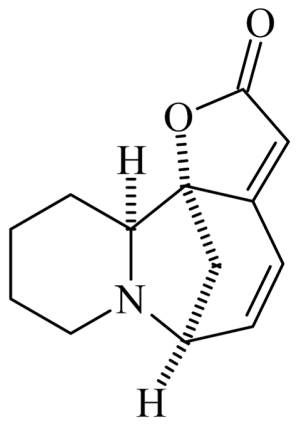

2

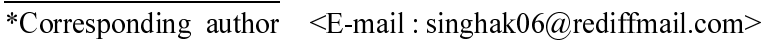

Fig. 1. Structure of securinine and allosecurinine. 
Table 1. Effect of securinine on spore germination of some fungi.

\begin{tabular}{|c|c|c|c|c|c|c|c|}
\hline \multirow{3}{*}{ Fungus } & \multirow{3}{*}{ Host } & \multicolumn{6}{|c|}{ Concentration (ppm) } \\
\hline & & \multicolumn{6}{|c|}{ Germination rate $(\%)$} \\
\hline & & Control & 200 & 400 & 600 & 800 & 1000 \\
\hline Alternaria alternata & Saprophyte & 95.50 & 88.50 & 87.17 & 54.50 & 50.50 & 0 \\
\hline Alternaria brassicae & Brassica compestris & 94.23 & 91.30 & 90.50 & 86.12 & 90.50 & 0 \\
\hline Alternaria brassicicola & Brassica oleracea & 98.80 & 0 & 0 & 0 & 0 & 0 \\
\hline Colletotrichum musae & Musa paradisiaca & 97.60 & 94.30 & 55.80 & 0 & 0 & 0 \\
\hline Colletotrichum sp. & Arundinaria falcata & 94.36 & 90.50 & 89.17 & 86.50 & 12.50 & 0 \\
\hline Curvularia lunata & Oryza sativa & 97.50 & 0 & 0 & 0 & 0 & 0 \\
\hline Curvularia maculans & Musa paradisiaca & 96.60 & 59.00 & 36.17 & 0 & 0 & 0 \\
\hline Curvularia pallenscens & Bambusa indica & 89.15 & 0 & 0 & 0 & 0 & 0 \\
\hline Erysiphe pisi & Pisum sativum & 97.20 & 80.50 & 79.50 & 60.12 & 40.20 & 26.30 \\
\hline Helminthosporium echinoclova & Echinochloa crusgalli & 98.45 & 86.20 & 76.12 & 55.30 & 36.12 & 16.23 \\
\hline Helminthosporium spiciferum & Solanum melongena & 90.12 & 0 & 0 & 0 & 0 & 0 \\
\hline Heterosporium sp. & Casia fistula & 90.68 & 76.45 & 60.36 & 24.68 & 14.80 & 0 \\
\hline
\end{tabular}

(1) (Fig. 1) (Manske, 1977) by direct comparison with an authentic sample (mmp, co-TLC and superimposable IR).

The fungi (Table 1) were isolated on PDA (peeled potato $250 \mathrm{~g}$, dextrose $20 \mathrm{~g}$, agar $15 \mathrm{~g}$, distilled water 1 liter) from their respective hosts collected from the experimental farm of Banaras Hindu University, Varanasi, India. The cultures were purified by single spore isolation technique on PDA slants and maintained by periodic transfer on the same medium for further experiments. Seven to ten days old cultures were used in this experiment. The spores of obligate parasitic fungi were directly picked up from their respective hosts.

The stock solution (2,000 ppm) was prepared by dissolving $10 \mathrm{mg}$ of the alkaloid securinine (1) initially with a few drops of methanol in a test tube. After the chemical was completely dissolved, approximately $5 \mathrm{ml}$ of distilled water was added. The solvent methanol was then evaporated on water bath. The required concentrations $(200,400,600,800$ and $1,000 \mathrm{ppm}$ ) of the chemical were prepared from the stock solution by diluting with distilled water. A drop $(30 \sim 40 \mathrm{ml})$ of the chemical solution was placed on a grease free glass slide. Fungal spores (about 200 300 spores) were mixed in a solution with the help of a sterile inoculation needle. E. pisi conidia were directly picked up from diseased plants and mixed in a solution. The slides were later placed in moist chamber made by placing two sterile moist filter papers on the lid and base of petri plates. The spores were then incubated at $25 \pm 2^{\circ} \mathrm{C}$. for $24 \mathrm{hr}$ for germination. The germination of the spores was observed after staining with Cotton blue prepared in lactophenol under a binocular light microscope (Nikon, Japan). All the experiments were conducted in triplicate.

\section{Results and Discussion}

The effect of securinine (1) on spore germination of some plant pathogenic fungi was studied (Table 1). The sensitivity of different fungi to this chemical varied consider- ably. Alternaria brassicicola, Curvularia lunata, Curvularia pallenscens and Helminthosporium spiciferum were the most sensitive as complete inhibition of germination was observed in all the concentrations $(200,400,600,800$ and $1,000 \mathrm{ppm}$ ) of the chemical. Similar effect on Curvularia maculans and Colletotrichum musae was recorded at 600, 800 and 1,000 ppm. However, only 1,000 ppm was effective against spore germination of Alternaria alternata, Alternaria brassicae, Colletotrichum sp. and Heterosporium sp. The chemical was mildly effective at all the concentrations studied against E. pisi and Helminthosporium echinoclova.

A number of alkaloids isolated from plants have already been reported in literature to possesses antifungal activity (Atta-ur-Rahman et al., 1997; Bracher, 1994; Goel et al., 2003).

We have reported the antifungal activity of the alkaloids, ent-norsecurinine (Goel et al., 2002), norsecurinine (Sahni et al., 2005) and allosecurinine (Singh et al., 2007) isolated from P. amarus. Securinine (1) and allosecurinine (2) (Fig. 1) are isomers whereas norsecurinine and ent-norsecurinine have different structures compared to compounds 1 and 2. Securinine inhibited complete spore germination of fungi $A$. brassicicola, C. lunata, C. pallenscens and $H$. spiciferum, whereas the alkaloid allosecurinine inhibited complete spore germination of fungi $C$. lunata, Collectotrichum sp., C. musae and Heterosporium sp. at very low concentrations. This is the first report of the antifungal activity of securinine, the fourth alkaloid isolated from P. amarus. The efficacy of the chemical is significantly high even at low concentrations which indicates a possibility of its use to control plant diseases under field conditions.

\section{References}

Atta-ur-Rahman, Nasreen, A., Akhtar, F., Shekhani, M. S., Clardy, 
J., Parvez, M. and Choudhary, M. I. 1997. Antifungal diterpenoidal alkaloids from Delphinium denudatum. J. Nat. Prod. 60: 474-475.

Bracher, E. 1994. Polycyclic aromatic alkaloids. Ten Annonaceous alkaloids with antimycotic activity. Arch. Pharm. Weincheim 327:371-375.

Goel, M., Maurya, S., Pandey, V. B., Singh, V. P., Singh, A. K. and Singh, U. P. 2002. Effect of ent-norsecurinine, an alkaloid, on spore germination of some fungi. Mycobiology 30:225-227.

Goel, M., Singh, U. P., Jha, R. N., Pandey, V. B. and Pandey, M. B. 2003. Individual and combined effect of $( \pm)$ - $\alpha$-hydrastine and $( \pm)$ - $\beta$-hydrastine on spore germination of some fungi. Folia Microbiol. 48:363-368.

Huang, Y. L., Chen, C. C. and Ou, J. C. 1992. Isolintetralin: a new lignan from Phyllanthus niruri. Planta Med. 58:473-474.

Joshi, B. S., Gawad, D. H., Pelletier, S. W., Kartha, G. and Bhandary, K. 1986. Isolation and structure (X-ray analysis) of ent-norsecurinine, an alkaloid from Phyllanthus niruri. J. Nat. Prod. 49:614-620.

Kobayashi, K., Nishirio, H., Fukushima, M. and Tomita, H. 1987. Antifungal activity of pisiferic acid and derivatives against rice blast fungus. Phytochemistry 26:3175-3179.

Manske, R. H. F. 1977. The Alkaloids. vol. XIV, pp. 425-506. Academic Press. New York and London.

Maurya, S., Srivastava, J. S., Jha, R. N., Pandey, V. B. and Singh, U. P. 2002. Efficacy of alkaloid (-)-corypalmine against spore germination of some fungi. Folia Microbiol. 47:287-290.

Maillard, M., Gupta, M. P. and Hosteltmann, K. 1987. A new antifungal prenylated fluronone from Erythrina berteroana.
Planta Med. 53:563-564.

Prithiviraj, B., Singh, U. P., Khiste, S. and Ram, D. 1996. Effect of methanol extract of Aegle marmelos leaves on Sclerotium rolfsii. Int. J. Pharm. 34:148-150.

Prithiviraj, B., Singh, U. P., Singh, K. P. and Schumacher, K. P. 1996. Field evaluation of ajoene, a constituent of garlic (Allium sativum) and neemazal, a product of neem (Azadirachta indica) against powdery mildew (Erysiphe pisi) of pea (Pisum sativum). Z. Pflanzenkrankh. Pflanzensch. 105:274-278.

Sahni, S., Maurya, S., Singh, U. P., Singh, A. K., Singh, V. P. and Pandey, V. B. 2005. Antifungal activity of norsecurinine against some phytopathogenic fungi. Mycobiology 33:97-103.

Sarma, B. K., Pandey, V. B., Misra, G. D. and Singh, U. P. 1999. Antifungal activity of berberine iodide, a constituent of Fumaria indica. Folia Microbiol. 44:164-166.

Singh, B., Agrawal, P. K. and Thakur, R. S. 1991. Isolation of trans-phytol from Phyllanthus niruri. Planta Med. 57:98.

Singh, U. P., Prithiviraj, B., Wagner, K. G. and Schumacher, K. P. 1995. Effect of ajoene, a constituent of garlic (Allium sativum) on powdery mildew (Erysiphe pisi) of pea (Pisum sativum). J. Plant Dis. Prot. 102:399-406.

Singh, U. P., Sarma, B. K., Misra, P. K. and Ray, A. B. 2000. Antifungal activity of venenatine, an indole alkaloid isolated from Alstonia venenata. Folia Microbiol. 45:173-176.

Thyagarajan, S. P., Subramanian, S., Thirunalasundari, T., Venkateswaran, P. S. and Blumberg, B. S. 1988. Effect of Phyllanthus amarus on chronic carriers of Hepatitis B virus. Lancet 2:764-766. 